\title{
Judicialização da política pública de saúde: interação entre o sistema político e o sistema jurídico na Região Sul do Brasil ${ }^{1}$
}

Public health policy judicial decision: interaction between political and legal system in Southern Region of Brazil

Judicialización de políticas de salud pública: interacción entre sistema político y judicial en la Región Sur del Brasil

\section{Liane Teresinha Schuh Pauli²}

RESUMO. Objetivo: Investigou-se a interação entre os sistemas jurídico e político, através do arcabouço legal e infralegal utilizado pelos autores, réus e juízes em processos de solicitação de medicamentos, insumos e internações. Metodologia: Estudo descritivoanalítico, de base qualitativa, realizado com dados primários acessados na Procuradoria Geral do Estado do Rio Grande do Sul, para analisar os processos sentenciados em primeira instância, nas Varas da Fazenda Pública da Capital, nos anos de 2012 e 2013. Resultados: $\mathrm{Na}$ amostra de 299 processos, apurou-se que 58,7\% solicitavam medicamentos, $24 \%$ insumos para saúde e $17,3 \%$ internações. Na fundamentação legal, os autores utilizaram portarias do Ministério da Saúde, bem como as Constituições Federal e Estadual, além da Lei no 8.080/90. Na contestação, o réu utilizou-se de resoluções da Comissão Intergestora Bipartite e portarias do Ministério da Saúde, entre outros. Os magistrados fundamentaram suas decisões na mesma legislação utilizada pelos autores e réus, não utilizando normas infralegais. Conclusão: Os profissionais da área jurídica utilizam basicamente a Constituição e normas legais, desprezando-se o arcabouço infralegal, onde está inserida a política pública.

Palavras-chave: Direito à Saúde. Políticas Públicas de Saúde. Judicialização da Saúde.

ABSTRACT. Objective: It was investigated the interaction between the legal and political systems, through the legal and infralegal framework used by authors, defendants and judges in cases of the ministration of medicines, pharmaceutical raw material and hospitalizations. Methodology: It's an analytical-descriptive study, of qualitative basis, conducted with primary data accessed on the Attorney General of the state of Rio Grande do Sul, to analyze the processes sentenced in the first instance, in the circuit from the Courts of the Public Treasury of the Capital, in the years 2012 and 2013. Results: In the sample of 299 cases, it was found that $58.7 \%$ asked for medicines, $24 \%$ pharmaceutical raw material and $17.3 \%$ of hospitalizations. In legal reasoning, the authors used ordinances of the Ministry of Health, as well as the Federal and State Constitutions, in addition to the Law 8080/90. In his defense, the defendant used resolutions from the Bipartite Intermanagement Commission and ordinances of MS, among others. The magistrates, justified their decisions in the same legislation used by the authors and defendants, not

\footnotetext{
1 Este artigo reflete os resultados da pesquisa sob mesmo título, executada pelo Programa de Direito Sanitário da Fundação Oswaldo Cruz em parceria com a UNISC, financiada pelo CNPq por intermédio do Termo de Concessão n.405016/2013-1

2 Doutora em Saúde Pública, Servidora da Secretaria Estadual de Saúde do Rio Grande do Sul SES-RS, Professor Adjunto da Universidade de Santa Cruz do Sul - UNISC, Departamento de Enfermagem e Odontologia, Santa Cruz do Sul, Rio Grande do Sul, Brasil. E-mail: pauli@usp.br
} 
using infralegal standards. Conclusion: The legal professionals use basically the constitution and legal norms, disregarding the infralegal framework where it is inserted the public policy.

Keywords: Right to Health. Public Health Policy. Judicialization of Health.

RESUMEN. Objetivo: Investigó si la interacción entre los sistemas jurídicos y políticos, a través del marco legal e infralegal utilizadas por los autores, los acusados y los jueces en processos de solicitude de medicamentos, insumos y hospitalizaciones. Metodología: Se realizó un estudio descriptivo-analitico, con la base cualitativa, realizado con datos primarios accede al Procurador General del estado de Rio Grande do Sul, para analizar los procesos condenado en primera instancia en las Varas de la Hacienda Pública de la Capital, en los años 2012 y 2013. Resultados: En la muestra de 299 casos, se comprobó que el $58,7 \%$ pide medicamentos, $24 \%$ de los insumos para la salud y el $17,3 \%$ de las hospitalizaciones. En la base legal, los autores usan las ordenanzas del Ministerio de Salud, así como las constituciones federal y estatal, además de la Ley 8080/90. En su defensa, el acusado utilizó las resoluciones de la Comisión Intergestora Bipartita y las ordenanzas de MS, entre otros. Los magistrados que justifiquen sus decisiones en la misma legislación utilizada por los autores y los acusados, no mediante normas infralegales. Conclusión: Los profesionales legales utilizar básicamente la Constitución y las normas legales, desprezando el marco Infralegal, donde se inserta la política pública.

Palabras-Ilave: Derecho a la Salud. Políticas Públicas de Salud. Judicialización de la Salud.

\section{Introdução}

O arcabouço normativo construído em torno do Direito à Saúde para concretizar os valores sociais determinados na Constituição Federal de 1988 (1), que visa permitir ao Sistema Único de Saúde (SUS) realizar sua efetiva gestão através das políticas públicas de saúde. O Poder Judiciário, por vezes, é acionado para a busca desse direito (2); estabelecendo que todas as decisões do Judiciário devam ser fundamentadas com elementos essenciais para a tomada de decisão (3).

O SUS é formado por um conjunto de normas jurídicas organizadas e sistematizadas a partir de princípios e regras dadas pela Constituição da República (1); possui um regime jurídico específico, que trata das questões relacionadas à saúde, voltadas à regulação das ações e serviços de interesse da sociedade e define a forma como o Estado se organiza para efetivação do direito à saúde (4).

$\mathrm{Na}$ ocorrência da necessidade da interrelação do sistema jurídico com o sistema político, deverão ser consideradas as normas definidoras da política pública de saúde, pois é no arcabouço infralegal que se define o regramento na política pública (5). 
A legislação do SUS, historicamente, construída seguindo os preceitos da Carta Magna (1), dispõe sobre a responsabilidade do Estado em prover a organização e o funcionamento dos serviços de saúde (6), e sobre a importância da participação da comunidade para fortalecer o controle social e a atuação do sistema (7).

Do conflito existente entre o sistema que constrói as políticas públicas para a saúde e o sistema do direito que impõe a atuação do Poder Judiciário, que a partir das demandas que the são apresentadas, como medicamentos, insumos para saúde e internação hospitalar, faz surgir o fenômeno jurídico-social a que se denominou "judicialização da saúde", e se traduz nos embates, demandas e discussões no campo do direito e da saúde.

A partir da pesquisa nacional e de sua relevância social, científica e técnica intitulada: "O arcabouço infralegal da política pública de saúde e sua observância pelo Poder Judiciário: interação entre o sistema político e o sistema jurídico", executado pelo Programa de Direito Sanitário (Prodisa), da Fundação Oswaldo Cruz de Brasília, financiada pelo Conselho Nacional de Desenvolvimento Científico e Tecnológico (CNPq), a qual contou com a parceria da Universidade de Santa Cruz do Sul (UNISC), e outras Instituições de Ensino Superior (IES) nas diferentes regiões, pode-se investigar a realidade da judicialização em cada estado do país.

Assim sendo, este artigo contempla as discussões sobre os achados da pesquisa, no que se refere aos argumentos utilizados pelos autores, réus e magistrados no âmbito do Estado do Rio Grande do Sul.

\section{Metodologia}

Foi realizado estudo descritivo-analítico documental, de natureza qualitativa (8), baseado em dados primários, em primeira instância, nas Varas de Fazenda Pública de Porto Alegre, capital do Rio Grande do Sul. As consultas foram realizadas para investigar a interação entre os sistemas jurídico e político, pelo uso das disposições legais e infralegais nas peças processuais, a saber: petições iniciais, contestações e sentenças, em processos de solicitação de medicamentos, insumos e internações. A unidade de análise foi 0 processo judicial sentenciado nos anos de 2012 e 2013.

Como critério de exclusão, não foram consideradas as demandas iniciadas e não sentenciadas no ano de referência, ações cuja parte ré não fosse o Estado do Rio Grande do Sul, bem como as demandas das Varas do Juizado Especial da Fazenda Pública e 
Juizados Especial da Fazenda Pública adjuntas, e os Juizados Especiais Cíveis, além de ações com pedido diverso ao objeto do estudo.

Embora o TJRS fornecesse levantamento informatizado das ações conforme orientação do Conselho Nacional de Justiça, em relação aos assuntos da área da saúde, a coleta de dados foi complementada efetivamente junto à Procuradoria Geral do Estado do Rio Grande do Sul (PGE/RS) por possuir sistema informatizado interno próprio de armazenamento de dados, no qual se encontraram os processos digitalizados em seu inteiro teor, pelo Sistema Themis.

Para atender ao objeto do estudo concentrou-se o trabalho na identificação e coleta dos fundamentos presentes nos processos envolvendo os três atores processuais, a saber: o autor, representado pelo paciente demandante, o réu, representado pelo procurador do Estado do RS e o juiz decisor. Os dados foram inseridos em planilhas e posteriormente exportadas para o Access.

Foi utilizado o método da análise de discurso de Laurence Bardin para a apreciação dos textos relativos às peças processuais da pesquisa (8).

O protocolo da pesquisa foi submetido e aprovado pelo Comitê de Ética em Pesquisa, da Faculdade de Ciências da Saúde da Universidade de Brasília, em 18.11.2014 sob o número 32553014.3.1001.0030.

\section{Resultados e discussão}

Foram identificados 213 processos do ano de 2012 e 241 processos no ano de 2013 e após a aplicação dos critérios de exclusão, obteve-se a amostra de 299 demandas validadas para análise.

Ramos (9), em sua pesquisa sobre a judicialização da saúde no estado da Bahia encontrou 120 processos relativos a 2012 e 2013. Com esta comparação pode-se afirmar que é superior as demandas judiciais na saúde no Estado do Rio Grande do Sul.

Na Região Sul, $100 \%$ das demandas foram individuais, das quais 59,2\% foram demandas iniciadas pela Defensoria Pública Estadual, representando os pacientes hipossuficientes, 98\% dos processos apresentaram pedido de antecipação de tutela, destes $91,6 \%$ julgados procedentes.

Da totalidade dos processos analisados, em $58,7 \%$ os pedidos se referiam a medicamentos, $24 \%$ a insumos para a saúde e $17,3 \%$ a internações hospitalares. 
No trabalho de pesquisa empreendido por Ramos (9), foram encontrados dados da judicialização da saúde na Bahia em que a maior parte dos pedidos se referiam a medicamentos, também. O trabalho da pesquisadora apontou que leitos de UTI, cirurgias e produtos para saúde foram os motivos mais demandados.

Observou-se que os autores utilizaram basicamente a Constituição Federal, a Constituição Estadual, e a Lei 8.080/90, nas suas petições iniciais. Em apenas 12,9\% foram utilizadas portarias do Ministério da Saúde e não houve utilização de resolução da Comissão Intergestora Bipartite (CIB) para o embasamento dos processos.

O Decreto ำ 7.508 de 2011, regulamenta a organização e funcionamento dos serviços e assistência em saúde que devem ser planejados e hierarquizados em Redes de Atenção à Saúde e pactuados conforme as responsabilidades de cada ente federativo na forma de Contrato Organizativo da Ação Pública da Saúde (COAP). Construído através do planejamento regional integrado, define a pactuação de metas, as referências, lista de medicamentos conforme a Relação Nacional de Medicamentos (RENAME) e os Protocolos Clínicos e Diretrizes Terapêuticas aprovados pelo Ministério da Saúde (10).

Em relação aos argumentos do réu, a título de contestação, observou-se que em $34,8 \%$ foram utilizadas as portarias do Ministério da Saúde e $12,1 \%$ as resoluções da CIB e a mesma legislação usada pelo autor. O principal argumento apresentado foi a insuficiência de recursos financeiros.

Segundo Ramos (9), o argumento econômico também foi o mais frequente na judicialização da Bahia, seguido de argumentos processuais, principiológicos e de gestão pública.

Nas decisões proferidas pelos magistrados, em nenhum processo observou-se a utilização de resolução da CIB.

As Comissões Intergestores, sendo a Comissão Intergestora Tripartite - CIT vinculada ao Ministério da Saúde, que envolve os três entes federados, a Comissão Intergestora Bipartite (CIB), no âmbito do Estado e municípios e a Comissão Intergestora Regional (CIR) no âmbito regional, aprovam através de resoluções, as referências e o financiamento das pactuações definidas para garantia da governança regional (10).

Foram utilizadas como embasamento jurídico, a legislação consolidada na Constituição Federal de 1988, também a Constituição Estadual do Rio Grande do Sul, a 
Lei no 8.080/90 e a Lei nำ 9.908/93. Também, citada a Lei no 10.741/03, a Lei № 12.134/04, Lei $n^{\circ} 8.078 / 90$ e na Lei $n^{\circ}=13.471 / 10$.

Os argumentos dos juízes encontrados no trabalho de Ramos (10) foram, principalmente principiológicos, restando o argumento da gestão pública nas sentenças, praticamente irrisório.

Com relação as normas que regulam as políticas públicas de saúde, observou-se a reduzida utilização da legislação infralegal, nas petições iniciais e na contestação do réu. Para a tomada de decisões, os magistrados, em suas sentenças, não utilizaram portarias do MS, tampouco as resoluções da CIB.

\section{Considerações Finais}

A complexidade da temática que envolve o direito à saúde exige dos profissionais que atuam direta ou indiretamente no SUS, a informação das rotinas do sistema, a atualização na legislação e o conhecimento sobre as normas gerais de fluxos dos contratos da organização pública de saúde, tornando-se imprescindível, na medida em que profissionais da área judiciária desconhecem a legislação e os fluxos nela apresentados (9).

As resoluções da CIR/CIB/CIT demonstram a organização das Políticas Públicas de Saúde para prestação de serviços em rede, as pactuações, as referências intermunicipais e regionais, as responsabilizações, os custos e os fluxos aprovados pela gestão pública do sistema de saúde nacional, estaduais, regionais e municipais. Condição sine qua non sua utilização para estabelecer a efetivação das questões em saúde, tanto no Executivo como no Judiciário. Sem a adequada fundamentação legislativa em todas as decisões, conforme o inciso IX do artigo 93 da Constituição Federal de 1988, a decisão pode se tornar nula.

Percebe-se cada vez mais, a relevância apresentada por Ramos (9), em discussões e questões educacionais interdisciplinares e intersetoriais, que devem ser implementadas para o exercício da autoridade, do controle, da administração e do poder de governança do Executivo e do Judiciário, em suas decisões referentes às questões do direito à saúde.

A porta de entrada do sistema não pode ocorrer dentro do Poder Judiciário, mas as necessidades dos usuários do sistema de saúde, devem iniciar por profissional e serviço credenciados no SUS. O processo judicial só deveria ocorrer somente após a negativa da prestação do serviço no sistema de saúde. 
Neste sentido, os Protocolos Clínicos e Diretrizes Terapêuticas, importantíssimos para a padronização, atualização e segurança dos diagnósticos e tratamentos, são também instrumentos de organização do SUS, passíveis de utilização pública e de ordenação de serviços (8). Infelizmente estes protocolos são praticamente inexistentes, mesmo sendo atos normativos de obrigação do Ministério da Saúde.

Assim, o Poder Judiciário acaba realizando políticas públicas por falta desse instrumento administrativo.

Pela análise do discurso percebe-se que o Poder Judiciário não compreende a linguagem e o arcabouço legal do SUS.

Necessário então, que se busque, a transparência do sistema de informações atualizadas, responsabilizando-se os órgãos competentes pela omissão por tais atualizações, devendo serem questionados pelo Poder Judiciário.

Existem ainda inúmeros desafios ao Estado e às várias instâncias colegiadas, no intuito de que sejam fortalecidas as questões administrativas e democráticas da gestão do SUS, utilizando-se a intersetorialidade entre o Executivo e o Judiciário, arena estatal de resolução de conflitos.

\section{Referências}

1. Brasil. Constituição da República Federativa do Brasil de 5 de outubro de 1988. Brasília: Senado Federal, 2013.

2. Aith FMA. Teoria Geral do Direito Sanitário Brasileiro. São Paulo: Programa de PósGraduação da Faculdade de Saúde Pública, Universidade de São Paulo; 2006.

3. Brasil. Lei no. 13.105 de 16 de março de 2015. Código de Processo Civil. Disponível em: http://www.planalto.gov.br/ccivil 03/ ato2015-2018/2015/lei//13105.htm [Acesso 19.nov.2016].

4. Dallari SG. A Construção do Direito à Saúde no Brasil. Revista de Direito Sanitário. 2009; 9(3): 9-34.

5. Delduque MC. O perfil ideal do juiz para as decisões em saúde. Cadernos lberoAmericanos de Direito Sanitário. 2012; 1(1): 30-43.

6. Brasil. Lei no. 8.080 de 19 de setembro de 1990. Dispõe sobre as condições para a promoção, proteção e recuperação da saúde, a organização e o funcionamento dos 
serviços correspondentes e dá outras providências. Disponível em http://www.planalto.gov.br/ccivil 03/leis//8080.htm [Acesso 19.set.2016].

7. Brasil. Lei n․ 8142 de 28 de dezembro de 1990. Dispõe sobre a participação da comunidade na gestão do Sistema Único de Saúde (SUS) e sobre as transferências intergovernamentais de recursos financeiros na área da saúde e dá outras providências. Disponível em http://conselho.saude.gov.br/legislacao/lei8142 281290.htm [Acesso 19.set.2016].

8. Bardin L. Análise de Conteúdo. Lisboa: Almedina, 2010.

9. Ramos, EMB. Argumentos dos autores processuais nas causas jurídicas sobre saúde no Estado da Bahia, Brasil. Cadernos Ibero-Americanos de Direito Sanitário. 2017; 6(1):127-138.

10. Brasil. Decreto $\mathrm{n}^{\circ}$. 7.508 de 28 de junho de 2011. Regulamenta a Lei $n^{\circ} \mathbf{8 . 0 8 0}$, de 19 de setembro de 1990, para dispo sobre a organização do Sistema Único de Saúde - SUS, o planejamento da saúde, a assistência à saúde e a articulação interfederativa, e dá outras providências. Disponível em http://www.planalto.gov.br/ccivil 03/ ato2011-

2014/2011/decreto/d7508.htm [Acesso 19.set.2016].

Recebido em:28.3.2018

Aprovado em: 29.3.2018

\section{Como citar este artigo:}

Pauli LTS. Judicialização da política pública de saúde: interação entre o sistema político e o sistema jurídico na Região Sul do Brasil. Revista Cadernos Ibero-Americanos de Direito Sanitário. 2018 jan./mar, 7(1):310317. 